2020-2

\title{
Disruptive Innovation: Impact for Practice, Policy, and Academia
}

Heather V. Nelson-Brantley

University of Kansas

K. David Bailey

University of California, Los Angeles

Joyce Batcheller

Texas Tech University Health Sciences Center

Laura Caramanica

University of West Georgia

Bret Lyman

Brigham Young University - Provo, bret-lyman@byu.edu

Follow this and additional works at: https://scholarsarchive.byu.edu/facpub

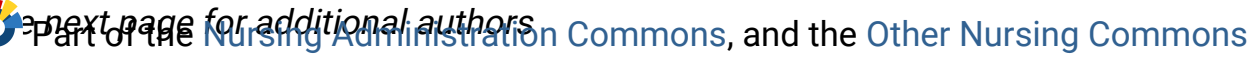

\section{Original Publication Citation}

Nelson-Brantley, H. V., Bailey, K. D., Batcheller, J., Caramanica, L., Lyman, B., \& Snow, F. (2020). Disruptive innovation: Impact for practice, policy, and academia. JONA: The Journal of Nursing Administration, 50(2), 63-65.

\section{BYU ScholarsArchive Citation}

Nelson-Brantley, Heather V.; Bailey, K. David; Batcheller, Joyce; Caramanica, Laura; Lyman, Bret; and Snow, Francine, "Disruptive Innovation: Impact for Practice, Policy, and Academia" (2020). Faculty Publications. 5063.

https://scholarsarchive.byu.edu/facpub/5063

This Peer-Reviewed Article is brought to you for free and open access by BYU ScholarsArchive. It has been accepted for inclusion in Faculty Publications by an authorized administrator of BYU ScholarsArchive. For more information, please contact ellen_amatangelo@byu.edu. 
Authors

Heather V. Nelson-Brantley, K. David Bailey, Joyce Batcheller, Laura Caramanica, Bret Lyman, and Francine Snow 


\title{
Disruptive Innovation: Impact for Practice, Policy, and Academia
}

\author{
Heather V. Nelson-Brantley, PhD, RN, NEA-BC, CCRN-K \\ K. David Bailey, PhD, RN, MBA, CCRN-K, NEA-BC, FACHE \\ Joyce Batcheller, DNP, RN, NEA-BC, FAAN \\ Laura Caramanica, PhD, RN, CENP, FACHE, FAAN \\ Bret Lyman, PhD, RN \\ Francine Snow, DrPH, MSN, CNE, RN-BC
}

The 2019 Association for Leadership Science in Nursing International Conference, Disruptive Innovation, was held in Los Angeles, California, with attendees from 30 US states, Canada, Brazil, and China. Presenters discussed the need for nurse leaders to advocate for health equity, lead evidence-based innovation, how robots and other technology are generating disruptive innovations in healthcare, and building strong academic-practice partnerships to address nursing workforce challenges.

Author Affiliations: Assistant Professor, University of Kansas School of Nursing (Dr Nelson-Brantley); Chief Nursing Officer, University of California Los Angeles, Santa Monica (Dr Bailey); Executive Nurse Advisor, Adjunct Professor, Center for the Advancement of Healthcare Professionals, AMN Healthcare \& Texas Tech University Health Sciences Center School of Nursing, Lubbock (Dr Batcheller); Associate Professor of Nursing, University of West Georgia, Carrollton (Dr Caramanica); Assistant Professor, Brigham Young University, Provo, Utah (Dr Lyman); and Assistant Professor of Nursing-Clinical, Cizik School of Nursing at The University of Texas Health Science Center at Houston (UTHealth) (Dr Snow).

The authors declare no conflicts of interest.

Correspondence: Dr Nelson-Brantley, 3901 Rainbow Boulevard, Mail Stop 4043 Kansas City, KS 66160 (hnelson-brantley@ kumc.edu).

DOI: 10.1097/NNA.0000000000000843
This article will report on these important insights.

Dr Linda Burnes Bolton, senior vice president and system chief health equity officer of Cedars Sinai Hospital, set the stage for the Association for Leadership Science in Nursing's (ALSN's) International Conference held in November of 2019. In her stirring call to action, she challenged nurses to carry more of the load in leading efforts to create a culture of health in the United States. Disruptive innovation is necessary to break the pervasive, pernicious cycles of health inequity and help everyone experience physical, emotional, and spiritual wellness-regardless of race, gender, or socioeconomic status. We must demystify pathways to health equity.

Dr Burnes Bolton proposed using population-oriented approaches to achieve a culture of health. To do so, nurses must attend to a broad range of factors that influence health, including discrimination, education, nutrition, clean water, secure housing, wealth, safe neighborhoods, and access to health and social services. Shaping these factors requires a variety of complex skills, such as assessing community needs, forming strategic partnerships with community organizations, collaborating interprofessionally, and evaluating programs. To create a culture of health, we must recognize that $70 \%$ of what causes us to be unhealthy is a result of social determinants of health. Nurses are exceptional in their ability to see and care for populations holistically; we must use this skill to be innovative and disrupt the status quo-think of healthcare teams in new ways. For example, when caring for individuals at home, include a maintenance worker on your team because they are critical to ensuring that the furnace is running, that the individual or family has running water, and that their social determinants of health are being addressed.

Nurses coleading these efforts should remember to value what matters to the individuals they are serving, not just reducing costs and improving quality metrics. It is about getting healthy and staying healthy. Dr Burnes Bolton closed by reminding nurse leaders of their capacity to change the world and by boldly inviting them to do so.

\section{Cultures of Innovation: Leading Evidence-Based Innovation}

Dr Daniel Weberg, head of clinical innovation at Trusted Health, invited 
nurse leaders to become innovators of evidence-based solutions. $\mathrm{He}$ challenged nurse leaders to "mash up" quality improvement science and innovation science. Quality improvement is a linear application of known evidence-based solutions to problems. Innovation involves nonlinear, often messy, thinking to generate new products. Combining linear and nonlinear problem-solving will generate true disruptive change.

Dr Weberg outlined 4 leadership skills for high performing teams: 1) positive deviance; 2) systems thinking; 3) network engineering; and 4) an operations mindset. Highperforming teams are innovative and performance driven; it is a symbiotic relationship. There are evidencebased approaches to innovation and change, and leaders must know them and use them.

He also dared nurse leaders to shift paradigms when engaging with nurses who create workarounds. Instead of a reprimand, offer recognition for identifying and attempting to fix broken parts of our systems. Nurse leaders must begin to see workarounds as a source of innovation. The job of the leader is to find the positive deviants and spread what they are doing.

Dr Weberg called for leadership to be a quality metric, because leadership is just as essential to a successful healthcare system as hospital acquired conditions. Toxic leadership demoralizes our nursing workforce and has a clear impact on patient outcomes. He also called on nurse leaders to transform nursing education. Care is leaving the hospital, yet most schools still predominately train nurses to practice in acute care hospitals.

The world is rapidly changing around us. Consumers want virtual, on-demand care anywhere. Wearables and smart phones collect health data, and consumers receive choices for care solutions in real time. The next innovation is waiting for a nurse leader willing to be a disruptive force. Dr Weberg concluded with a call to actioncreate disruptive innovation or be left behind.

\section{Robots, Nurses, and Patients, Oh My: An Innovative Workforce Solution}

Dr Cole Edmonson, chief clinical officer for AMN Healthcare, and Dr Andrea Thomaz, chief executive officer and cofounder of Digital Robotics, presented on the disruptive innovation of using robots to assist in healthcare, resulting in a return of valuable time to nurses. In his former chief nursing officer role, Dr Edmonson invited Digital Robotics to demonstrate how Moxi, a collaborative robot, could assist the clinical team with various tasks. Dr Thomaz and her team met with the nursing department to determine which tasks Moxi would perform. Tasks assigned to Moxi included delivering supplies to the patient's room upon a nurse's request, transporting laboratory specimens to the laboratory, transporting medications from the pharmacy in a secure manner, and collecting soiled linen bags from designated areas.

Dr Edmonson shared how this disruptive innovation resulted in a significant reduction in nurses' workload because of the tasks assigned to Moxi. During the trial, nurses gained an average of 150 minutes per day of additional time for nursing care. Additional outcomes included improved employee satisfaction, improved patient satisfaction, and improved workflow between departments. Disruptive innovations such as Moxi may provide one solution with helping nurses find joy in their work by reducing the tasks that often take multiple hours per day away from caring for patients at the bedside.

\section{Innovative Academic and Practice Partnerships}

Dr Joyce Batcheller, nurse executive advisor for the Center for the Advancement of Healthcare Professionals, Dr Barbara Cherry, associate dean and department chair for leadership studies at Texas Tech University, and Dr Patricia YoderWise, president of the Wise Group, led a panel discussion on their innovative work to build academicpractice partnerships to support the current and future nursing workforce in Texas. The panel described how 3 key forces are converging at roughly the same time: 1 ) a proliferation of new nursing programs; 2) the next iteration of the NCLEX prelicensure examination; and 3) the work in progress on the re-envisioned AACN Essentials. This prompted the panel to ask if these efforts should be examined for alignment and possible impact on practice.

The panel is taking a disruptive innovation approach to deliberate on these issues by bringing together key constitutes in academia, service, practice, policy, and governance, as well as nursing students and frontline nurses. In 2020, they will host a summit, Stakeholders Moving Toward Alignment, that brings together key stakeholders in academia and practice with the goal of providing recommendations. The summit will use the World Café ${ }^{1}$ approach to facilitate group dialogue with structured questions to shape the future through conversations that matter. Although this work is being led in Texas, as many conference attendees shared, the 
challenges are similar across the nation. The panel ended with a call to action for nurse leaders in academia and practice in other states to partner in addressing these challenges in their own states and nationally.

\section{Future Directions for ALSN}

The business meeting provided an opportunity for ALSN members to reflect on the accomplishments of the past year and future directions of the organization. In 2019, the organization adopted a new name, the
Association for Leadership Science in Nursing. The American Organization of Nurse Executives changed their name shortly after to the American Organization of Nurse Leaders. The year has seen a growing partnership between the 2 organizations, including a joint Delphi study to identify the research priorities for nursing leadership science. In addition, ALSN membership has increased by more than $20 \%$, and more than $63 \%$ of those who attended the ALSN Conference were 1st-time attendees. Combined, these outcomes signal a promising future for nursing leadership practice, education, and research. We look forward to seeing you at the 2020 ALSN International Conference!

\section{REFERENCE}

1. The World Café. Café to go: a quick reference guide for hosting world café. 2015. http://www.theworldcafe.com/wp-content/ uploads/2015/07/Cafe-To-Go-Revised. pdf. Accessed October 31, 2019. 